\title{
INFLUÊNCIA DA ESTRUTURA DE GOVERNANÇA CORPORATIVA NA EFICIÊNCIA FINANCEIRA: EVIDÊNCIAS DE EMPRESAS BRASILEIRAS DE CAPITAL ABERTO
}

\section{RESUMO}

Este estudo objetiva verificar a influência da governança corporativa na eficiência financeira de empresas brasileiras com ações listadas na Bovespa. De natureza quantitativa-descritiva, foram analisados dados de 284 empresas no período de 2008 a 2013 para verificar a evolução ao longo dos anos da eficiência financeira e, do ano de 2013, para estimar a influência da governança corporativa. Avaliou-se a governança corporativa a partir da criação de um índice de governança (Igov), proposto por Silveira (2004), para as dimensões acesso às informações, conteúdo das informações públicas, estrutura do Conselho de Administração e estrutura de propriedade e controle. $\mathrm{O}$ cálculo da eficiência financeira das empresas foi realizado utilizando a Análise por Envoltória de Dados (DEA) e, para sua análise, empregou-se a técnica de análise de redes sociais com o software Uncinet 6.0 e o pacote estatístico Stata 11.0. Como resultados, verificou-se que a eficiência financeira dos bancos, ao longo dos seis anos analisados, manteve-se estável e superior ao das empresas, tanto em relação ao percentual equivalente de empresas com eficiência máxima, quanto em relação ao índice geral de eficiência. Verificou-se, que a governança corporativa influencia o desempenho financeiro das empresas negativamente na dimensão estrutura do Conselho de Administração e positivamente pela estrutura de propriedade. Os resultados para os bancos evidenciaram a influência positiva do acesso às informações e negativa para o conteúdo das informações e para a estrutura do Conselho de Administração. Este estudo contribui para identificação das dimensões da governança corporativa que influenciam a eficiência de empresas e bancos e também coopera com a identificação de instituições eficientes ao longo de seis anos.

Palavras-chave: Eficiência financeira; Empresas de capital aberto; Governança corporativa.

\section{INFLUENCE OF STRUCTURE OF CORPORATE GOVERNANCE IN FINANCIAL PERFORMANCE: EVIDENCE OF BRAZILIAN COMPANIES OPEN CAPITAL}

\section{ABSTRACT}

This study aims to investigate the influence of corporate governance in financial efficiency of Brazilian companies listed on the BOVESPA. Quantitative-descriptive, 284 companies were analyzed data from 2008 to 2013 to check the evolution over the years of financial efficiency and, in the year 2013 to estimate the influence of corporate governance. We evaluated the corporate governance through the creation of a governance index (IGOV), proposed by Silveira (2004), for the dimensions access to information content of public information, structure of the board of directors and ownership and control structure. The calculation of the financial efficiency of the companies was carried out by using the data envelopment analysis (DEA) and to his analysis, he used the social networking analysis technique with 6.0 UNCINET software and the statistical package STATA 11.0. As a result it was found that the financial efficiency of the banks, over the six years analyzed, remained stable and higher than the companies, both in relation to the equivalent percentage of companies with maximum efficiency, as compared to the overall rate of efficiency. It was found that the corporate governance influences the financial performance of companies negatively in the size structure of the board and positively by the ownership structure. The results for banks showed the positive influence of access to information and negative for the information content and the structure of the board. This study helps to identify the dimensions of corporate governance that influence the efficiency of companies and banks and also cooperates with the identification of effective institutions over six years.

Keywords: Corporate Governance; Financial Efficiency; Public Companies. 


\section{INFLUENCIA DE LA ESTRUCTURA DE GOBIERNO CORPORATIVO EN DESEMPEÑO FINANCIERO: EVIDENCIA DE EMPRESAS BRASILEÑAS DE CAPITAL ABIERTO}

\section{RESUMEN}

Este estudio tiene como objetivo investigar la influencia de la gobernanza empresarial en la eficiencia financiera de las empresas brasileñas que cotizan en la BOVESPA. -Cuantitativa descriptiva, se analizaron 284 empresas los datos de 2008 a 2013 para comprobar la evolución en los últimos años de la eficiencia financiera y, en el año 2013 para estimar la influencia del gobierno corporativo. Se evaluó la gestión empresarial a través de la creación de un índice de gobernabilidad (Igov), propuesto por Silveira (2004), por las dimensiones acceso al contenido de la información pública, la estructura del consejo de administración, estructura de propiedad y control. El cálculo de la eficiencia financiera de las empresas se llevó a cabo mediante el análisis envolvente de datos (DEA) y para su análisis, utilizó la técnica de análisis de redes sociales con 6,0 software UNCINET y el paquete estadístico STATA 11.0. Como resultado se encontró que la eficiencia financiera de los bancos, durante los seis años analizados, se mantuvo estable y más alta que las compañías, tanto en relación con el porcentaje equivalente de empresas con la máxima eficiencia, en comparación con la tasa global de eficiencia. Se encontró que el gobierno corporativo influye en los resultados financieros de las empresas negativamente en la estructura de tallas de la junta y de forma positiva por la estructura de propiedad. Los resultados para los bancos mostraron la influencia positiva de acceso a la información y negativo para el contenido de la información y la estructura de la junta. Este estudio ayuda a identificar las dimensiones de gobierno corporativo que influyen en la eficiencia de las empresas y los bancos, también coopera con la identificación de instituciones eficaces de más de seis años.

Palabras clave: Gobierno Corporativo; Eficiencia Financiera; Empresas Públicas.

Tatiana Marceda Bach ${ }^{1}$ Claudineia Kudlawicz ${ }^{2}$ Eduardo Damião da Silva ${ }^{3}$

\footnotetext{
1 Doutoranda em Administração pela Pontifícia Universidade Católica do Paraná - PUCPR. Mestre em Administração pela Universidade Regional de Blumenau - FURB. Brasil. E-mail: tatibach@gmail.com

${ }^{2}$ Doutoranda em Administração pela Pontifícia Universidade Católica do Paraná - PUCPR. Brasil. E-mail: kclaudineia@gmail.com

${ }^{3}$ Doutor em Programa Ph.D. In Management Sciences pela Escuela Superior de Administración y Dirección de Empresas - Esade, Barcelona. Professor da Pontifícia Universidade Católica do Paraná - PUC/PR. Brasil. E-mail: eduardo.damiao@pucpr.br
} 


\section{INTRODUÇÃO}

Cada vez mais no mundo, as organizações adotam padrões de governança corporativa, como resultado do interesse de gestores, acionistas, investidores, órgãos reguladores e a sociedade em geral sobre estas práticas (Demirbas \& Yukhanaev, 2011). No Brasil, a adoção destas condudas é realizada, em sua maioria, por corporações do mercado financeiro aberto, como forma de atrair capital estrangeiro, tornarem-se mais competitivas (Demirbas \& Yukhanaev, 2011) e reduzirem o impacto de eventuais desequilíbrios econômicos em seu desempenho. Sobre isso, Catapan e Colauto (2014) argumentam que quanto maior a evidenciação das informações referentes a governança corporativa, maior é o valor representativo da companhia para o mercado.

Uma das formas de avaliar a representatividade da empresa é por meio de sua eficiência financeira, quando os custos gerados são superados pelas receitas, ao ponto de serem mais rentáveis e apresentarem menor risco financeiro e a uma maior atratividade para o mercado financeiro (Berger, Hunter \& Timme, 1993; Berger \& Humphrey, 1997; Berger \& Mester, 1997). A eficiência financeira de uma companhia é mensurada em termos de custos e receitas gerados pela empresa, que, em si, espera-se uma maior rentabilidade da gestão financeira, mas que se reflete também em oferecer bens de qualidade, a tornar a companhia competitiva e reduzir os riscos (Berger, Hunter \& Timme, 1993; Berger \& Humphrey, 1997; Berger \& Mester, 1997).

A relação entre governança corporativa e eficiência das empresas foi objeto de diferentes investigações (Peixoto, Ferreira \& Lopes, 2011; Ferreira, 2012; Ferreira et al. 2013; Peixoto, 2012; Bernardino, Peixoto \& Ferreira; 2015) no entanto, em alguns estudos esta relação não foi confirmada. Por conta disso, neste artigo pretende-se verificar a influência da governança corporativa na eficiência financeira de 284 empresas brasileiras com ações listadas na Bovespa.

A governança corporativa foi avaliada pela criação do índice Igov, conforme proposto por Silveira (2004), para as dimensões acesso às informações, conteúdo das informações públicas, estrutura do Conselho de Administração e estrutura de propriedade e controle. A eficiência financeira foi calculada, por meio da Análise por Envoltória de Dados (DEA) e serviu como base para análise de redes de relacionamentos entre empresas e bancos que obtiveram níveis máximos de eficiências.
Este estudo, encontra-se estruturado em quatro seções, além desta introdução: na primeira, é apresentada a revisão de literatura sobre estratégia e estrutura de governança corporativa e eficiência financeira; na segunda, são descritos os materiais e métodos empregados; na terceira, apresenta-se a discussão e análise dos dados e, na quarta, são expostas as considerações finais.

\section{REVISÃO DE LITERATURA}

\subsection{Estratégia e estrutura de governança corporativa}

No campo da Administração Estratégica, os estudos sobre governança corporativa surgiram, principalmente, a partir da obra de Berle e Means (1932), que averiguou a influência dos conflitos de estrutura e propriedade no desempenho e no valor acionário de grandes companhias norte-americanas. No entanto, esta temática passou a ser investigada com maior profundidade no ano de 2002, como consequência da divulgação de descobertas de fraudes contábeis que envolviam grandes corporações, tais como Enron, Worldcom, Xerox, Vivendi, Royal Ahold e Parmalat (Silveira, 2004). Embora estudos sobre governança corporativa tenham recebido atenção nos últimos anos, em razão de falhas relacionadas a sua gestão e de mudanças em sua atuação, ainda é uma temática importante em função do papel que sua estrutura representa para evitar custos e problemas de agência (Adams, Hermalin \& Weisbach, 2010).

Cada vez mais as organizações do mundo realizam alterações em sua estrutura para adotarem padrões de governança corporativa, pois, além de este assunto despertar o interesse de gestores, acionistas e investidores, também tem atraído a atenção de órgãos reguladores e da sociedade em geral, principalmente em observar se as organizações estão sendo gerenciadas de forma eficiente, eficaz e com ética (Demirbas \& Yukhanaev, 2011). Em razão da atenção dada pelos diferentes atores, a adoção de padrões aceitos de governança corporativa torna-se um elemento essencial para que as empresas possam lidar com dificuldades atreladas a governança, a atrair capital estrangeiro e tornarem-se nacionalmente e internacionalmente mais competitivas (Demirbas \& Yukhanaev, 2011).

O impulso para disseminação internacional dos padrões aceitos de governança corporativa ocorreu, inicialmente, no ano de 1999 e foi readequado em 2004. Nesta época, a Organização para Cooperação e Desenvolvimento Econômico 
(Ocde) divulgou o código de governança corporativa e dos princípios globais de governabilidade elaborado pela Ocde, por órgãos governamentais de diferentes países e outras organizações do setor público e privado. Em conformidade com este código, a definição de governança corporativa consistia em estimular o Conselho de Administração e a gestão da companhia a promoverem os objetivos organizacionais de interesse, tanto da companhia quanto de seus acionistas, e realizar o seu controle de forma eficaz (Ocde, 2004).

$\mathrm{O}$ argumento principal da Ocde consistia em regulamentar a governança corporativa nos países vinculados e não vinculados a Ocde e fornecer informações para as bolsas de valores mundiais, investidores e outros interessados. A partir disso, poderia-se criar um ambiente de confiança, internamente e externamente, para o bom funcionamento da companhia no mercado, resultando em menores custos de capital, ao uso dos recursos de modo eficiente e a maiores taxas de crescimento (OCDE, 2004).

No Brasil, o Instituto Brasileiro de Governança Corporativa (Ibcg), fundado em 1995, regulamenta os princípios de governança corporativa e atua na disseminação de maior transparência, de critérios justos e atuação responsável das companhias brasileiras (Ibcg, 2010). Para tal, a governança corporativa se refere a um sistema de direção, monitoramento e incentivo de companhias, aliado à relacionamentos entre [...]proprietários, conselho de administração, diretoria e órgãos de controle" (Ibcg, 2010, p. 19). Sob este ponto de vista, as condutas adotadas pelos atores visam aliar interesses e contribuir para o crescimento e a longevidade da companhia.

A governança corporativa também pode ser entendida como um conjunto de mecanismos, internos e externos à organização, de incentivo e de controle, que objetivam maximizar o retorno dos fornecedores de recursos em relação ao que estes investiram (Silveira, 2004). Por conta disso, existe uma tendência das empresas reavaliarem suas condutas e harmonizarem suas ações, como resultado de pressões para adoção de normas de governança corporativa (Demirbas \& Yukhanaev, 2011). A governança corporativa promove um conjunto de relações entre a direção da empresa, o Conselho de Administração, os acionistas e demais interessados para atuarem no sentido de adotarem as melhores práticas (Demirbas \& Yukhanaev, 2011). Sobre isso, Melkumov (2009) salienta que quando as organizações se comportam em conformidade com regras institucionais elas aumentam suas chances de sobrevivência, ao atuar de acordo com as convenções aceitas socialmente.
O foco da governança corporativa está em gerenciar mecanismos benéficos a esta relação, como a configuração de uma gestão que execute as atividades corretamente, que disponibilize informações que refletem a realidade e que criem um ambiente de confiança entre os interessados, deste modo, proverão vantagens nesta relação (Eisenhard, 1989). Os mecanismos de governança, que refletem os interesses dos gestores e dos acionistas, podem ser compreendidos como: formação de um Conselho da Administração, criação de uma estrutura de propriedade e controle, criação e uma política de remuneração ao conselho, à diretoria, aos agentes e acionistas, presença de informações relativas a estrutura de capital, possibilidade de competição no mercado de produtos e de mão de obra dos gestores e a publicação periódica de relatórios financeiros e informativos relevantes aos acionistas (Silveira, 2004).

A compreensão do papel do Conselho de Administração ajudaria a entender as políticas de regulamento de atividades empresariais (Adams, Hermalin \& Weisbach, 2010), pois alterações em seus membros poderão modificar a forma com que as práticas são realizadas. De modo geral, possuir um Conselho de Administração segue uma regra legal instituída pelos princípios de governança corporativa (Adams, Hermalin \& Weisbach, 2010) e ao possuir uma estrutura adequada poderá ter maior qualidade na tomada de decisões estratégicas, visando um melhor acompanhamento da gestão executiva. Essencialmente, sua atuação consiste em fornecer uma direção estratégica e controlar a gestão dos executivos da companhia (Demirbas \& Yukhanaev, 2011).

É esperado que um Conselho de Administração atue na supervisão da administração executiva em relação aos negócios, riscos e pessoas, com objetivo final de gerar benefícios aos acionistas, quando equilibrar os interesses dos acionistas com os da companhia (Demirbas \& Yukhanaev, 2011; IBCG, 2010). Desse modo, o Conselho de Administração também realiza o monitoramento sistemático de como as estratégias corporativas são desenvolvidas na companhia, além de prestar contas aos sócios sobre relatórios e demonstrações financeiras (Melkumov, 2009; Ibcg, 2010). A estrutura de propriedade se refere a maior concentração da posse das ações nos gestores e conselheiros, o qual, segue determinadas normas de governança para evitar que apenas um indivíduo tenha o controle total da companhia (Silveira, 2004) e que cada sócio proprietário de ações tenha o direito de votar conforme a quantidade de ações representadas por ele (Ibcg, 2010). 
Sobre os instrumentos de governança corporativa, Demirbas e Yukhanaev (2011) salientam que um dos principais fatores que apresenta influência no desempenho da organização refere-se a remuneração do conselho, da diretoria, dos agentes e acionistas, fato este que é associado ao desempenho profissional de cada um. Quando a organização divulga seus relatórios financeiros aos acionistas e ao mercado, contemplando informações exigidas em lei e complementares, ela se torna competitiva em termos de produtos e/ou serviços e passa a seguir princípios internacionais de governança corporativa, relevantes para ampliar mercados e se integrar no mercado financeiro global (Demirbas \& Yukhanaev, 2011; Silveira, 2004; Ibcg, 2010). Ademais, a divulgação das informações possibilita com que múltiplos atores possam ter acesso ao conteúdo das informações técnicas e financeiras da companhia e, por meio delas, realizar projeções e tomar decisões sobre investir, fato este que está associado ao melhor desempenho da empresa (Kumar \& Zattoni, 2013).

\subsection{Eficiência financeira}

Ao ser eficiente financeiramente, a companhia se torna efetiva em relação aos custos gerados e a suas receitas, ao ponto de uma maior rentabilidade da gestão financeira conduzir a um menor risco financeiro e a uma maior atratividade para o mercado financeiro (Berger, Hunter \& Timme, 1993; Berger \& Humphrey, 1997; Berger \& Mester, 1997). A eficiência financeira de uma companhia é mensurada em termos de custos e receitas gerados pela empresa, que, por sua vez, devem resultar não apenas em uma maior rentabilidade da gestão financeira, mas também na oferta de bens de qualidade, de modo que a companhia seja competitiva e tenha seus riscos reduzidos (Berger, Hunter \& Timme, 1993; Berger \& Humphrey, 1997; Berger \& Mester, 1997).

Do mesmo modo, quando a eficiência financeira for baixa, maiores serão os riscos incorridos no desempenho financeiro da companhia. A respeito disso, Williamson (1996) argumenta que a conduta do agente e a eficiência da firma são complementares e essa conduta está relacionada, principalmente, em como suas atividades econômicas são organizadas e coordenadas e a atuação das estruturas de governança é realizada com o propósito de reduzir os custos de transação dos agentes econômicos.

A eficiência das empresas pode ser medida por meio do modelo de Análise por Envoltória de Dados (DEA). Esse modelo permite avaliar a eficiência das companhias a partir da comparação entre informações financeiras e contábeis (Kassai,
2002) e oferece informações relevantes para os agentes, os acionistas, proprietários ou gestores e demais interessados a respeito de como os recursos estão sendo gerenciados. Seus indicadores de medida por podem ser realizados pelo retorno sobre os ativos (Roa), retorno sobre os investimentos (Roi), retorno sobre o capital empregado (Roce) ou retorno sobre o patrimônio líquido (RSPL), receita operacional (RO), tamanho do ativo total e crescimento da receita, Q de Tobin e o lucro antes dos juros, impostos, depreciação e amortização (Lajirda) (Carneiro \& Silva, 2010; Ferreira, 2012).

\subsection{Desenvolvimento conceitual e hipóteses}

No contexto brasileiro, diversos estudos avaliaram a relação entre governança corporativa e eficiência. Ao realizar um comparativo entre empresas que adotam práticas de governança corporativa, Ferreira (2012) e Ferreira et al. (2013) não encontraram indícios de que empresas que adotam condutas de governança corporativa apresentam maior eficiência e de que se verificou diferença entre eficiência técnica. Em um cenário anterior e posterior à crise financeira, Peixoto (2012) não encontrou indícios de que uma maior governança corporativa conduz a um desempenho superior, este último representado pelo valor e risco.

Ao analisar a estrutura de governança corporativa, Sonza (2012) identificou que a eficiência das empresas era influenciada negativamente quando o presidente do Conselho de Administração também era o executivo da companhia. Por outro lado, Sonza e Kloeckner (2014) verificaram que a remuneração dos executivos, a posse de ações por estes e a presença de conselheiros independentes aumentavam a eficiência das empresas. Evidências de relações positivas entre a governança corporativa e a eficiência financeira foram encontradas no estudo de Peixoto, Ferreira e Lopes (2011) de Bernardino, Peixoto e Ferreira (2015).

Bernardino, Peixoto e Ferreira (2015) verificaram que as empresas do setor elétrico brasileiro que adotam práticas de governança corporativa também se apresentam como mais eficientes. No mercado financeiro, empresas que divulgam suas informações e adotam os princípios de governança corporativa poderão ser visualizadas como de menores riscos, assim atraem mais investidores (Demirbas \& Yukhanaev, 2011) e estes, ao investirem seu capital na companhia, contribuem para seu melhor desempenho financeiro. Com base no argumento apresentado, sustenta-se, neste estudo, que empresas com maiores índices de governança corporativa também 
poderão apresentar uma maior eficiência financeira (Bernardino, Peixoto \& Ferreira, 2015). No entanto, esse estudo se difere dos demais analisados ao verificar a influência da governança corporativa fracionada em suas dimensões: acesso às informações, conteúdo das informações públicas, estrutura do Conselho de Administração e estrutura de propriedade e controle. Deste modo, as hipóteses que norteiam este estudo são:

H1: Na governança corporativa, o acesso às informações influencia a eficiência financeira;

H2: A governança corporativa e o conteúdo das informações públicas influenciam a eficiência financeira;

H3: Na governança corporativa e a estrutura do Conselho de Administração influenciam a eficiência financeira;

H4: Na governança corporativa, a estrutura de propriedade e controle influenciam a eficiência financeira.

\section{MATERIAIS E MÉTODOS}

Ao analisar a influência da estrutura de governança corporativa na eficiência das empresas, esta pesquisa se configura, no que tange a natureza do estudo, como teórica-empírica. A abordagem do problema é quantitativa-descritiva ao empregar métodos estatísticos. Quanto aos procedimentos de coleta, extraíram-se do banco de dados do sistema Economática dados secundários de 403 empresas com ações listadas na Bolsa de Valores de São Paulo (BM\&FBovespa) para calcular a eficiência financeira. A perspectiva temporal empregada foi transversal com perspectiva longitudinal, uma vez que as informações referentes a eficiência compreenderam eventos que ocorreram ao longo de seis anos, de 2008 à 2013, e os dados de governança corporativa compreenderam a informações do ano de 2013.

Os dados coletados consistiram no nome da ação, na Receita Bruta (faturamento), no Lucro Operacional Bruto (Lob), no Lucro Operacional Líquido (Lol), no Lucro das Operações Continuadas (Loc), no Patrimônio Líquido (PL), no tamanho do Ativo Total (AT) e no setor de atividade. Foram constatadas, ao final da coleta, a ausência de algumas informações em determinados períodos e, considerando que os dados se configuram de forma temporal, excluíram-se 119 empresas. Ao final, compuseram a amostra um total de 284 empresas, destas 16 eram instituições financeiras.

Outras informações foram obtidas efetuando-se cálculos. O Resultado sobre o Patrimônio Líquido (Rspl) foi obtido a partir do modelo matemático representado na Equação 1:

Equação 1:

$$
R S P L=\frac{L L}{P L}
$$

Onde:

RSPL $=$ Resultado sobre o Patrimônio Líquido

$L L=$ Lucro Líquido

O cálculo da eficiência financeira das empresas foi realizado utilizando a metodologia matemática não-paramétrica da Análise por Envoltória de Dados (Dea), que avalia a eficiência relativa de Unidades Tomadoras de Decisão ou Decision Making Units (Dmu) semelhantes, formadas pela comparação de informações sobre quantidades de recursos utilizados (inputs) e bens produzidos (outputs) (Charnes, Cooper \& Rhodes, 1978). Para estimar a DEA, empregou-se o modelo
Ccr que considera os retornos constantes das variáveis de escala a partir da soma ponderada dos produtos em relação a soma ponderada dos insumos, obtendo um resultado com variação entre 0 e 1. Desta forma, cria-se uma fronteira eficiente que indica os elementos mais eficientes e os menos ineficientes de uma escala de produção, ou, no caso deste estudo, financeiros (Peña, 2008). Este modelo pode ser visualizado na Equação 2:

\section{Equação 2:}




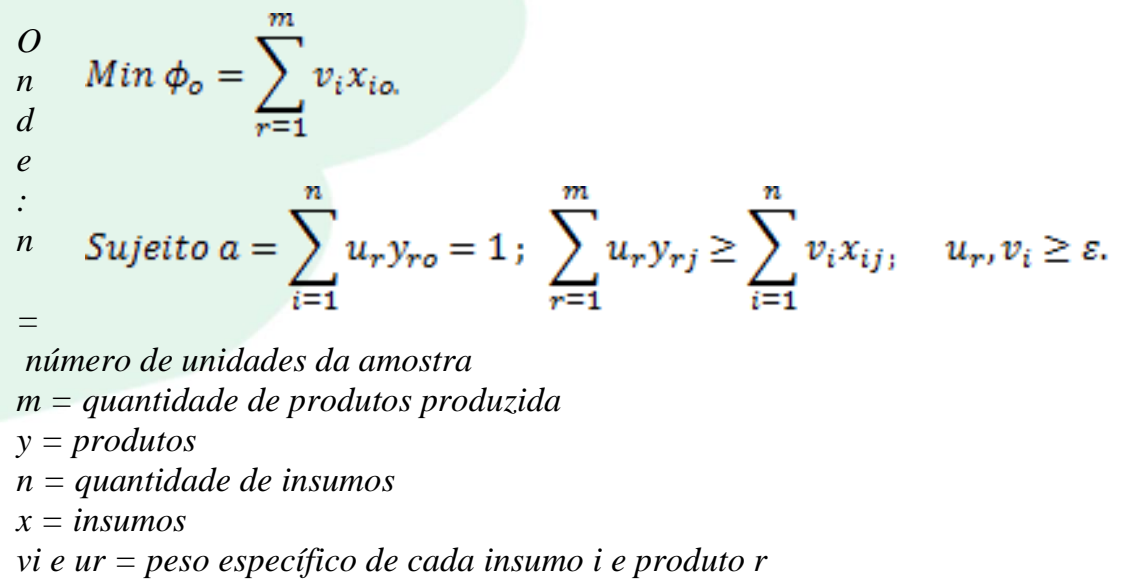

$\mathrm{O}$ valor de $\mathrm{n}$ corresponde ao número de unidades da amostra (DMU), estes produzem uma quantidade $m$ de produtos $y$, por meio de quantidades $n$ de insumos $x$. Uma unidade $o$ produz yro quantidades de produtos, por meio do uso de xio insumos. A solução de Peña (2008) se concentra na obtenção dos valores para vi e ur (que indica o peso específico de cada insumo $i$ e produto $r$ ) desse modo, para que a medida de eficiência para a unidade produtiva analisada seja maximizada é necessário que as medidas de eficiência de todas as unidades sejam menores ou iguais a 1 . O valor máximo obtido por meio deste modelo é 1 e menor é zero.

A eficiência financeira das empresas foi calculada utilizando-se o software Dea Frontier adicionado à planilha eletrônica Excel e, com ajuda da ferramenta Solver, geraram-se os modelos Dea. Com base no estudo de Beuren, Nascimento e Rocha (2013) selecionaram-se as variáveis para o cálculo da eficiência que sugerem uma variável de entrada (input) e três de saída (outputs), conforme informa a figura 1 .

\begin{tabular}{|l|l|l|l|}
\hline \multicolumn{2}{|c|}{ Input (x) } & \multicolumn{2}{c|}{ Outputs (y) } \\
\hline \multirow{2}{*}{ X1 } & \multirow{2}{*}{ Receita Bruta (Faturamento) } & Y1 & Lucro Operacional Líquido (LOL) \\
\cline { 3 - 4 } & Y2 & Lucro Operacional Bruto (LOB) \\
\cline { 3 - 4 } & Y3 & Resultado sobre o Patrimônio Líquido \\
\hline
\end{tabular}

Figura 1 - Seleção das variáveis para aplicação do modelo DEA

Fonte: Beuren, Nascimento e Rocha (2013)

Considerando que a metodologia da Dea sugere como inputs a quantidade de recursos utilizados e como outputs os bens produzidos, optou-se, por se tratarem de dados financeiros, por utilizar o faturamento como inputs e os resultados financeiros gerados como outputs, seguindo as recomendações de Beuren, Nascimento e Rocha (2013). Como critérios de semelhança de escolha das Dmus, considerou-se as empresas brasileiras de capital aberto com ações negociadas na Bovespa, das quais, mensurou-se o desempenho financeiro comparando informações financeiras e contábeis e, com base em sua aplicação, gerou um índice que indica as empresas eficientes e as ineficientes, variando entre 0 para as menos eficientes e 1 para as mais eficientes (Kassai, 2002).

Após identificadas as empresas eficientes ao longo do período analisado, foi aplicada estatística baseada em redes sociais. Este procedimento foi realizado com o propósito de verificar a existência de centralidade e intermediação das empresas em relação ao total da amostra. Com o auxílio do software Ucinet 6.0, foi elaborada a rede de relações entre as empresas de cada período, enfatizando a sua posição. No software, foram calculados o grau de centralidade das empresas, o de intermediação e as estatísticas descritivas das empresas que obtiveram eficiência de $100 \%$. Para esta análise, optou-se por realizá-la somente com as empresas, em razão da maior quantidade de atores para analisar ao longo do período, dessa forma, excluíram-se as instituições financeiras desta análise.

Para criar o índice de governança (Igov) foi utilizado o modelo proposto por Silveira (2004). A autora considerou, na construção do índice, quatro 
dimensões baseadas nos estudos de Jensen (2001) e nas recomendações do Ibcg e da Cvm: acesso às informações, conteúdo das informações, estrutura do Conselho de Administração e estrutura de propriedade e controle.
A figura 2 apresenta as perguntas utilizadas como base para construção do índice de governança corporativa.

\begin{tabular}{|c|c|}
\hline $\begin{array}{l}\text { Dimensão de } \\
\text { Governança }\end{array}$ & Perguntas para a construção do índice de governança corporativa \\
\hline \multirow{7}{*}{$\begin{array}{c}\text { Acesso às } \\
\text { informações }\end{array}$} & 1.1 É possível obter o relatório anual (RA) da empresa por meio da internet? \\
\hline & 1.2 A empresa possui website? \\
\hline & $1.3 \mathrm{O}$ website dispõe de documentos relativos a governança corporativa? \\
\hline & $\begin{array}{l}\text { 1.4 O website dispõe de apresentações para analistas ou dados que possibilitem projeções } \\
\text { operacionais e financeiras da empresa? }\end{array}$ \\
\hline & $1.5 \mathrm{O}$ website é bilíngue? \\
\hline & $1.6 \mathrm{O}$ website possui uma seção de relações com os investidores? \\
\hline & 1.7 Obtiveram-se as informações sem a necessidade de contato direto com a empresa? \\
\hline \multirow{4}{*}{$\begin{array}{l}\text { Conteúdo das } \\
\text { informações } \\
\text { públicas }\end{array}$} & 2.1 O RA inclui seção dedicada à implementação de princípios de Governança Corporativa? \\
\hline & 2.2 Os demonstrativos são apresentados em US-Gaap ou Ias-Gap? \\
\hline & $\begin{array}{l}2.3 \mathrm{O} \text { RA, website ou algum outro documento corporativo apresentam } \\
\text { adicionado/destruído pelo negócio? }\end{array}$ \\
\hline & 2.4 A empresa produz e publica seus relatórios financeiros legalmente na data exigida? \\
\hline \multirow{5}{*}{$\begin{array}{c}\text { Estrutura do } \\
\text { Conselho de } \\
\text { Administração }\end{array}$} & $\begin{array}{l}\text { 3.1 Os cargos de diretor executivo e presidente do Conselho de Administração são ocupados por } \\
\text { pessoas diferentes? }\end{array}$ \\
\hline & 3.2 A empresa possui um Conselho de Administração com 5 a 9 membros? \\
\hline & 3.3 Mais que $80 \%$ do Conselho de Administração é composto por conselheiros externos? \\
\hline & 3.4 O Conselho de Administração possui mandato unificado de um ou dois anos? \\
\hline & 3.5 A empresa possui acordo ou acordo de acionista? \\
\hline \multirow{5}{*}{$\begin{array}{l}\text { Estrutura de } \\
\text { propriedade e } \\
\text { controle }\end{array}$} & 4.1 A empresa emite apenas ações com direito a voto $(\mathrm{ON})$ ? \\
\hline & 4.2 As ações preferenciais correspondem a menos que $50 \%$ do total de ações ordinárias? \\
\hline & $4.3 \mathrm{O}(\mathrm{s})$ controlador(es) possui $(\mathrm{em})$ menos do que $70 \%$ do total de ações ordinárias? \\
\hline & 4.4 A empresa concede tag along aos detentores de ações preferenciais? \\
\hline & 4.5 A empresa emite ADR e lista suas ações na Bolsa de Nova Iorque? \\
\hline
\end{tabular}

Figura 2 - Perguntas para a construção do índice de governança corporativa

Fonte: Silveira (2004) e com base em recomendações do código de melhores práticas de governança corporativa do IBGC e da CVM.

O índice de governança foi calculado a partir da atribuição de respostas binárias (0 e 1) para cada uma das 21 perguntas. Desta forma, quando a empresa possuía a informação, era atribuído o peso 1 e, quando ausente, o peso 0. Para obtenção das respostas, foram consultados o site da Bolsa de Valores de São Paulo (Bovespa), o site das empresas e seu Estatuto Social. No site da Bovespa foram analisadas as informações pertinentes a Posição Acionária, Ações em Circulação no Mercado, Composição do Capital Social, os Relatórios da Administração, as Notas Explicativas, o Balanço Patrimonial, a Demonstração do Resultado, a Demonstração do Valor Adicionado, as Informações Trimestrais (ITR), a Emissão de ADR e a adesão ao Tag Along. No site e no Estatuto Social das empresas, foram analisadas as seções relacionadas ao Relacionamento com Investidores (RI), de Governança Corporativa, Informativos Financeiros e informações relativas à Composição do Conselho da Administração, da Diretoria Executiva e do Estatuto Social. Após a análise e categorização de cada item, obteve-se um total de respostas para cada empresa. Em seguida, foi criado um índice, a partir da divisão das respostas obtidas pelo total de perguntas do instrumento de coleta. As variáveis utilizadas para análise foram:

a) Governança corporativa: Variável independente representada pela atribuição do índice de governança (Igov) conforme proposta de Silveira (2004) para cada dimensão: acesso às informações, conteúdo das informações, estrutura do Conselho 
de Administração e estrutura de propriedade e controle. Estas informações compreenderam ao ano de 2013;

b) Eficiência financeira: Variável independente obtida por meio do cálculo das companhias e com o auxílio da Dea. Considerou-se como input o faturamento no final de 2013 e como outputs o Lucro Operacional Líquido (Lol), Lucro Operacional Bruto (Lob) e o Resultado sobre o Patrimônio Líquido (Rspl) (Beuren, Nascimento \& Rocha, 2013);

c) Setor de atuação: Variável dependente que compreende a divisão dos setores aos quais as empresas encontram-se vinculadas: de agro e pesca, alimentos e bebidas, comércio, construção, eletroeletrônicos, energia elétrica, seguros, máquinas indústria, mineração, minerais não metalizados, não cadastrados, papel e celulose, petróleo e gás, química, siderurgia e metalurgia, software e dados, telecomunicações, têxtil, transporte e serviços, veículos e peças e finanças.

A análise dos dados foi realizada em duas etapas: a primeira, compreendeu a análise das empresas e a segunda, a análise das instituições financeiras. Efetuou-se em separado esta análise em razão da estrutura de capital e da atividade dos bancos apresentarem características diferenciadas.

O software estatístico Stata versão 11.0 foi utilizado para realizar a análise dos dados e calcular as estatísticas descritivas, o valor de Vif, o teste Hettest e a regressão linear com método de estimação dos Mínimos Quadrados Ordinários (Mqo). Esta última foi calculada para identificar as relações entre as variáveis e verificar a influência das independentes nas dependentes. Ressalta-se que na análise utilizou-se o Igov e a eficiência financeira para o ano de 2013, pois, para construção do índice Igov, as perguntas somente poderiam ser respondidas no ano específico ao da coleta de dados, impossibilitando que se analisassem algumas questões em relatórios dos anos anteriores. Calculou-se o modelo de regressão linear, apresentado na Equação 3, com base em Maroco (2003).

\section{Equação 3:}

$$
Y j=\beta o+\beta_{1} X_{1 j}+\beta_{2} X_{2}+\ldots+\beta p X p j+E j(j=1, \ldots, n)
$$

O método empregado neste estudo foi construído conforme protocolo visualizado na figura 3.

\begin{tabular}{|c|c|c|c|}
\hline Etapa & Procedimento & Método & Objetivo \\
\hline \multirow[b]{3}{*}{$\begin{array}{l}\text { Método de coleta } \\
\text { de dados } \\
\text { secundários }\end{array}$} & \multirow{2}{*}{$\begin{array}{c}\text { Elaborar a base de } \\
\text { dados brutos para } \\
\text { dar suporte ao } \\
\text { cálculo da } \\
\text { eficiência } \\
\text { financeira. }\end{array}$} & $\begin{array}{c}\text { Informações coletadas no sistema } \\
\text { Economática (2008 a 2013): nome } \\
\text { ação, faturamento, Lob, Lol, Loc, PL, } \\
\text { AT e setor. }\end{array}$ & \multirow{2}{*}{$\begin{array}{l}\text { Calcular a eficiência } \\
\text { financeira das } \\
\text { empresas utilizando } \\
\text { software DEA } \\
\text { Frontier adicionado à } \\
\text { planilha eletrônica } \\
\text { Excel. }\end{array}$} \\
\hline & & Cálculo do Rspl & \\
\hline & $\begin{array}{c}\text { Elaborar a base de } \\
\text { dados brutos que } \\
\text { compõe o Igov, } \\
\text { composto por } 4 \\
\text { dimensões e } 21 \\
\text { perguntas. }\end{array}$ & $\begin{array}{l}\text { Informações coletadas no site da } \\
\text { Bovespa (ano de 2013): posição } \\
\text { acionária, ações em circulação, } \\
\text { composição do capital social, relatórios } \\
\text { da administração, notas explicativas, } \\
\text { balanço patrimonial, Dre, valor } \\
\text { adicionado, Itr, Adr e Tag Along. No } \\
\text { site das empresas, coletaram-se, na } \\
\text { seção RI, GC, Informativos Financeiros } \\
\text { do Conselho de Administração, da } \\
\text { Diretoria Executiva, bem como o } \\
\text { Estatuto Social. }\end{array}$ & $\begin{array}{l}\text { Criar o índice Igov } \\
\text { por meio da } \\
\text { atribuição de } 1 \text { para } \\
\text { possuir a informação } \\
\text { e 0, quando não } \\
\text { possuir. }\end{array}$ \\
\hline Etapa & & Método & Objetivo \\
\hline Método de análise & \multicolumn{2}{|c|}{ Para empresas eficientes, calculou-se a estatística baseada em } & Verificar a existência \\
\hline
\end{tabular}


Influência da Estrutura de Governança Corporativa na Eficiência Financeira: Evidências de Empresas

Brasileiras de Capital Aberto

\begin{tabular}{|c|c|c|}
\hline dos dados & $\begin{array}{c}\text { redes sociais e a rede de empresas eficientes ao nível 100\% } \\
\text { para cada período (grau de centralidade e intermediação). } \\
\text { Utilizou-se o software Ucinet } 6.0\end{array}$ & $\begin{array}{c}\text { de centralidade e } \\
\text { intermediação das } \\
\text { empresas }\end{array}$ \\
\cline { 2 - 3 } & Calculou-se as estatísticas descritivas, o valor de Vif, o teste & $\begin{array}{c}\text { Verificar a relação } \\
\text { entre a eficiência } \\
\text { financeira e a } \\
\text { governança } \\
\text { corporativa }\end{array}$ \\
\hline
\end{tabular}

Figura 3 - Protocolo de condução desta pesquisa

Fonte: Elaborado pelos autores (2015)

Os dados foram apresentados em tabelas, gráficos e figuras. Tendo em vista o objetivo da pesquisa, a análise das empresas e dos bancos foi realizada de forma separada.

\section{DISCUSSÃO E ANÁLISE DOS DADOS}

\subsection{Apresentação dos resultados para as empresas não financeiras}

4.1.1 Análise da eficiência financeira das empresas
Foram identificadas as 268 empresas eficientes e ineficientes em relação às variáveis Faturamento, Lol, Lob e Rspl para cada período analisado (2008 a 2013). Neste sentido, valores próximos de 1 são considerados eficientes e próximos de zero, ineficientes. A Figura 4 ilustra a evolução da eficiência das empresas. Apresentaram-se, no gráfico, para melhor visualização, as empresas com eficiência entre 0,7 a $1,0$ (ou $70 \%$ a $100 \%)$.

Eficiência das empresas para o ano de 2008
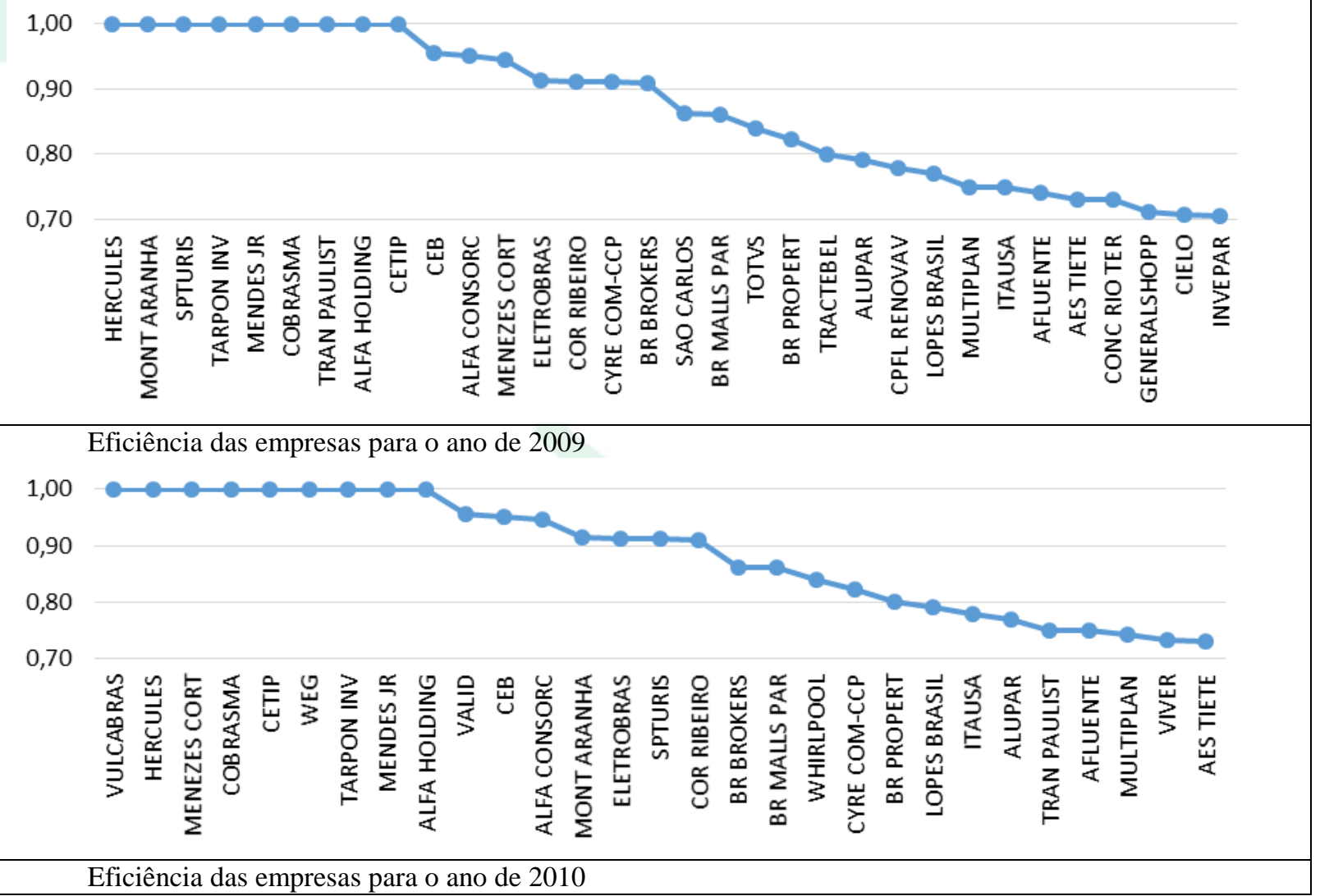

Eficiência das empresas para o ano de 2010 
Influência da Estrutura de Governança Corporativa na Eficiência Financeira: Evidências de Empresas

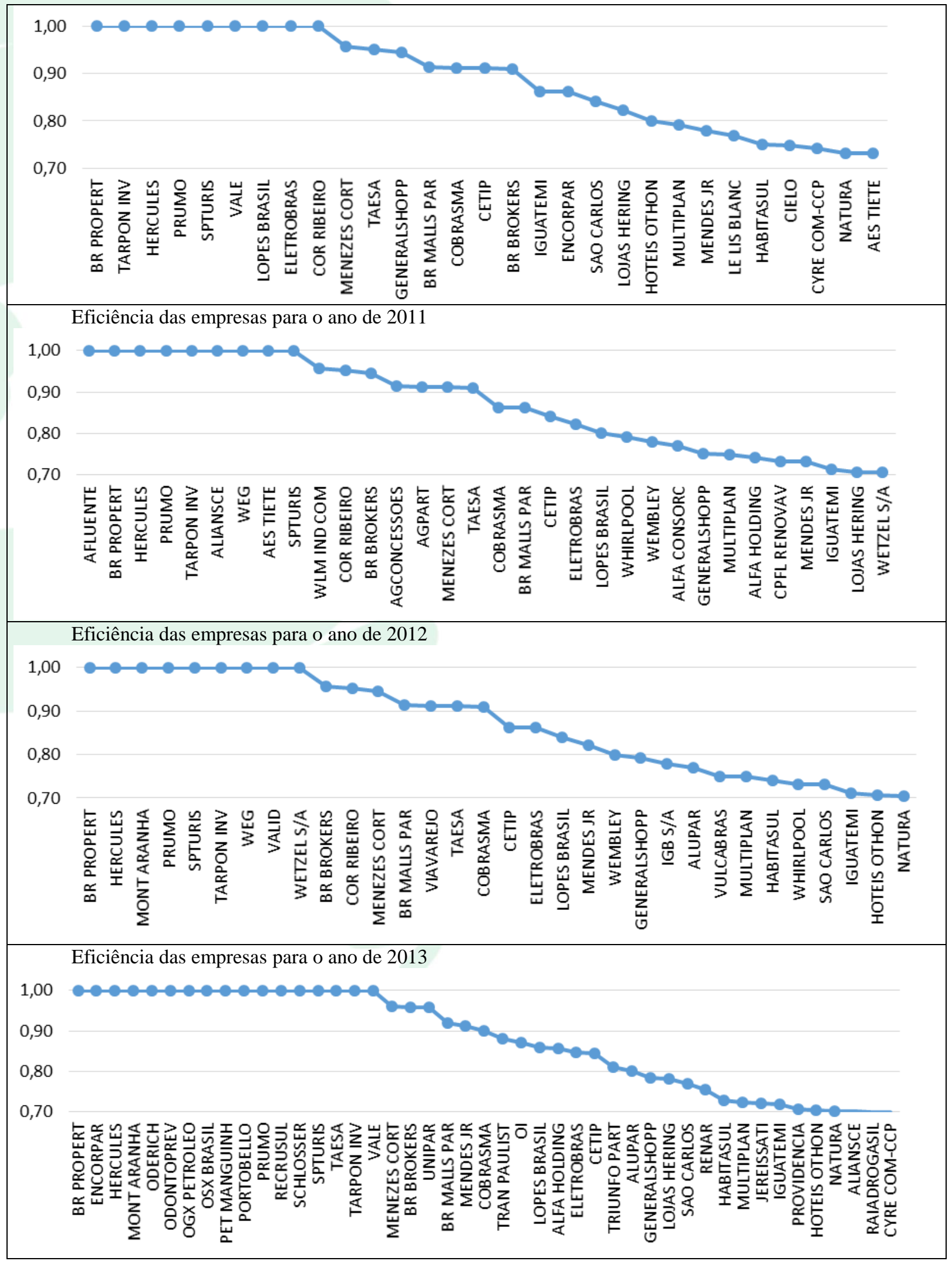

Figura 4 - Evolução das eficiências das empresas no período de 2008 a 2013

Fonte: Dados da pesquisa 
Os dados da Figura 4 ilustram que, entre os períodos iniciais (2008 e 2009), houve um número considerável de empresas que mantiveram eficiência ao nível de 0,7 e 1,0, um total de 33 e 34 empresas. Neste período, as eficientes em $100 \%$ totalizaram 14 e 15 empresas, resultando em um dos maiores índices do período analisado. Este resultado pode estar atrelado à política do governo no ano de 2007, a qual realizou modificação das Subvenções e Assistências Governamentais (SAG), passando estas a serem contabilizadas na conta da Demonstração do Resultado do Exercício (DRE), e que contribuiu para o maior resultado empresarial (Iudícibus, et al. 2010).

Esse resultado corrobora com os achados de Loureiro, Gallon e De Luca (2011) que, ao investigarem 88 companhias de capital aberto em 2008 e 2009, verificaram o recebimento de incentivos financeiros por empresas que disponibilizaram informações referentes à SAG em suas demonstrações financeiras e contábeis. No estudo de Loureiro, Gallon e De Luca (2011), mais de $50 \%$ destas empresas foram contempladas pela SAG oriundas da união, recebendo incentivos em impostos federais, principalmente relacionados a redução do pagamento do Imposto de Renda de Pessoa Jurídica (IRPJ). As empresas que mais receberam incentivos financeiros eram vinculadas aos setores têxtil, de energia, bens de consumo, telecomunicações e química e petroquímica e apresentaram maior rentabilidade. Ademais, elas apresentaram variações em seus índices financeiros, com aumento de $0,2 \%$ para o retorno sobre o ativo (ROA), 0,4\% para o retorno sobre o patrimônio líquido (ROE) e $0,3 \%$ para o retorno sobre as vendas (ROS).

No ano de 2010, por sua vez, houve uma redução na quantidade de empresas, de forma que, 29 obtiveram eficiência entre 0,70 e 1,00, representando uma queda de $14,7 \%$ se comparado com o período anterior. As empresas que obtiveram eficiência máxima em 2010, totalizaram 7, fato que também ocasionou uma redução de 46,6\% em relação ao total de empresas eficientes em 100\% para o ano de 2009. Esta redução pode ser reflexo da crise financeira internacional ocorrida, em 2008, com a falência do Banco Americano Lehman Brothers, o que ocasionou grandes perdas financeiras, de mercado e o enfraquecimento da moeda americana e, consequentemente, de países Latino-Americanos (Farhi \& Borghi, 2009).

$\mathrm{O}$ índice de eficiência financeira apresentou aumento na quantidade das empresas nos anos mais recentes. Em 2011, o número de empresas eficientes ao nível de 0,70 e 1,00 foi de 34; em 2012 foi de 32 e em 2013, 45. O nível máximo de eficiência ocorreu em 10 empresas para 2011; em 9 para 2012 e em 17 para 2013. Se comparar a eficiência ao nível de $100 \%$ do ano de 2010 com os demais períodos, houve um aumento de $30 \%$ para 2011; de $22 \%$ para 2012 e de $59 \%$ para 2013. A partir desse resultado, pode-se inferir que houve uma evolução na quantidade de empresas eficientes, principalmente pelo fato de 2013 ter apresentado uma maior inserção de empresas e destas, a maior quantidade de todo o período se tornou eficiente ao nível de $100 \%$ (17). Esse aumento pode estar vinculado com a necessidade, percebida pelas companhias, de sofisticação e melhores combinações dos ativos tangíveis e intangíveis, o que contribui para uma maior geração de valor e desempenho (Perez \& Famá, 2006). Entretanto, se comparar o ano de 2013 com os anos de 2008 e 2009, se constatará que houve um aumento de duas empresas.

As demais empresas analisadas, não visualizadas na Figura 5, totalizaram os seguintes resultados: para o ano de 2013, 211 empresas obtiveram nível de eficiência que variaram entre 0,68 e 0,01 e 12 foram consideradas ineficientes ao índice 0\%. Em 2012, o total de empresas que apresentaram índice de eficiência entre 0,69 e 0,02 foi de 224, sendo que as ineficientes somaram 12. Para o ano de 2011, 225 empresas obtiveram índices entre 0,69 e 0,01 e as ineficientes somaram 9. Para o ano de 2010, houveram 231 com nível variando entre 0,68 e 0,01 e as ineficientes totalizaram 8. No ano de 2009, 223 apresentaram níveis entre 0,69 e 0,04 , enquanto as ineficientes (0\%) totalizaram 11. Por fim, o ano de 2008 obteve 227 empresas com variação entre 0,69 e 0,01 e as ineficientes, 8.

Ressalta-se que a análise da Figura 4 foi realizada considerando os percentuais de aumento ou redução em relação a variações que ocorreram nos anos. A representatividade das empresas eficientes ao nível de $100 \%$ em relação ao total de empresas da amostra foi de 5,2\% para $2008 ; 5,5 \%$ para $2009 ; 2,6 \%$ para $2010 ; 3,7 \%$ para $2011 ; 3,5 \%$ para 2012 e $6,3 \%$ para o ano de 2013. A aplicação do modelo DEA permitiu identificar as empresas mais eficientes em relação as variáveis analisadas e o comportamento delas ao longo de seis anos. Esse dado se torna relevante, principalmente, para acionistas, proprietários ou gestores, sobre o desempenho das empresas em relação a forma com que os recursos estão sendo empregados, além disso, para as empresas ineficientes, se percebe a necessidade de adotar estratégias para modificar o indicador apresentado.

Com o propósito de analisar as empresas que se tornaram eficientes em mais de um período e, verificar o seu posicionamento, gerou-se, com 
Influência da Estrutura de Governança Corporativa na Eficiência Financeira: Evidências de Empresas Brasileiras de Capital Aberto

auxílio do software Ucinet 6.0, a Figura 5 que ilustra esta relação.

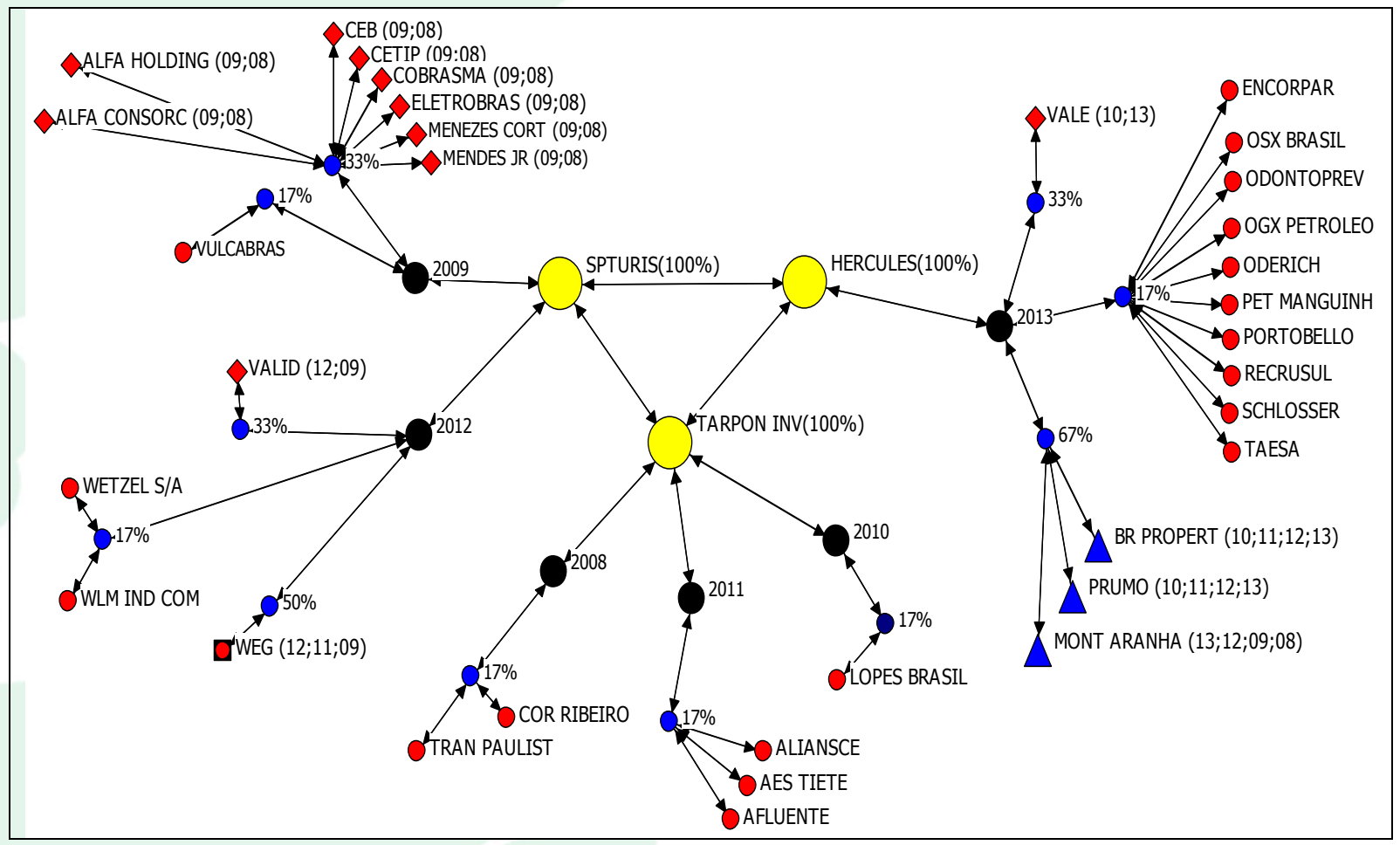

Figura 5 - Posição das empresas eficientes ao nível de 100\%, entre os anos de 2008 e 2013

Fonte: Dados da pesquisa

Para complementar as informações apresentadas na Figura 6, elaborou-se a Tabela 1 que apresenta as empresas eficientes em $100 \%$ em cada período de análise. Ressalta-se que, para uma melhor visualização, optou-se por apresentar as empresas eficientes em dois ou mais anos.

Tabela 1 - Total de empresas eficientes em $100 \%$ ao longo dos anos

\begin{tabular}{|c|c|c|c|c|c|c|c|}
\hline Empresa & $\mathbf{2 0 0 8}$ & $\mathbf{2 0 0 9}$ & $\mathbf{2 0 1 0}$ & $\mathbf{2 0 1 1}$ & $\mathbf{2 0 1 2}$ & $\mathbf{2 0 1 3}$ & Total \\
\hline Hercules & 1 & 1 & 1 & 1 & 1 & 1 & 6 \\
\hline Spturis & 1 & 1 & 1 & 1 & 1 & 1 & 6 \\
\hline Tarpon Inv & 1 & 1 & 1 & 1 & 1 & 1 & 6 \\
\hline Br Propert & - & - & 1 & 1 & 1 & 1 & 4 \\
\hline Mont Aranha & 1 & 1 & - & - & 1 & 1 & 4 \\
\hline Prumo & - & - & 1 & 1 & 1 & 1 & 4 \\
\hline Weg & - & 1 & - & 1 & 1 & - & 3 \\
\hline Menezes Cort & 1 & 1 & - & - & - & - & 2 \\
\hline Mendes JR. & 1 & 1 & - & - & - & - & 2 \\
\hline Cobrasma & 1 & 1 & - & - & - & - & 2 \\
\hline Alfa Holding & 1 & 1 & - & - & - & - & 2 \\
\hline Cetip & 1 & 1 & - & - & - & - & 2 \\
\hline Valid & - & 1 & - & - & 1 & - & 2 \\
\hline Ceb & 1 & 1 & - & - & - & - & 2 \\
\hline Alfa Consorc & 1 & 1 & - & - & - & - & 2 \\
\hline
\end{tabular}

\begin{tabular}{|c|c|c|c|c|c|c|c|}
\hline Empresa & $\mathbf{2 0 0 8}$ & $\mathbf{2 0 0 9}$ & $\mathbf{2 0 1 0}$ & $\mathbf{2 0 1 1}$ & $\mathbf{2 0 1 2}$ & $\mathbf{2 0 1 3}$ & Total \\
\hline Vale & - & - & 1 & - & - & 1 & 2 \\
\hline Eletrobras & 1 & 1 & - & - & - & - & 2 \\
\hline Afluente & - & - & - & 1 & - & - & 1 \\
\hline Vulcabrás & - & 1 & - & - & - & - & 1 \\
\hline Encorpar & - & - & - & - & - & 1 & 1 \\
\hline Oderich & - & - & - & - & - & 1 & 1 \\
\hline Odontoprev & - & - & - & - & - & 1 & 1 \\
\hline OGX Petroleo & - & - & - & - & - & 1 & 1 \\
\hline OSX Brasil & - & - & - & - & - & 1 & 1 \\
\hline Pet Manguinh & - & - & - & - & - & 1 & 1 \\
\hline Portobello & - & - & - & - & - & 1 & 1 \\
\hline Recrusul & - & - & - & - & - & 1 & 1 \\
\hline Schlosser & - & - & - & - & - & 1 & 1 \\
\hline Taesa & - & - & - & - & - & 1 & 1 \\
\hline- & - & - & - & - & - & - & - \\
\hline
\end{tabular}

Fonte: Dados da pesquisa 
No período analisado, as empresas Spturis, Hercules e Tarpon Inv (destacadas na cor amarela na Figura 1) se apresentaram eficientes em todos os anos analisados, ou seja, alcançaram o índice máximo de eficiência financeira, $100 \%$ de 2008 a 2013 (Tabela 1). Essas empresas, mantiveram seu indicador de desempenho entre os melhores do total da amostra, fato que contribuiu para o desempenho financeiro.

Outras empresas revelaram eficiência financeira máxima por um período de 4 dos 6 anos analisados. Entre elas, podem ser citadas: a $\mathrm{Br}$ Propert e a Prumo (destacadas na forma de triângulo azul) eficientes (100\%) nos anos de 2010, 2011, 2012 e 2013 (Tabela 1). Além delas, a Mont Aranha mostrou-se eficiente (100\%) em 2008, 2009, 2012 e 2013. Estas empresas representam um total de $67 \%$ de eficiência financeira máxima quando comparada sua representatividade em quatro dos seis anos.

A empresa Weg mostrou-se eficiente em $100 \%$ por três anos $(2009,2011$ e 2012), o que representou, ao longo de seis anos, $50 \%$ de eficiência. As empresas que apresentaram índice de $100 \%$ em dois anos consecutivos (2008 e 2009), visualizadas no canto superior esquerdo da figura, foram: Alfa Consorc, Alfa Holding, Ceb, Cetip, Cobrasma, Eletrobrás, Menezes Cort e Mendes JR. Do mesmo modo, a empresa Valid apresentou êxito nos anos de 2009 e 2012, enquanto a empresa Vale se destacou em 2010 e 2013.

As empresas consideradas eficientes em um ano dos seis analisados foram: a) para o ano de 2013 (17\%): Encorpar, Osx Brasil, OdontoPrev, Ogx Petróleo, Oderich, Pet Manguinh, Portobello, Recrusul, Schlosser e Taesa; b) para o ano de 2012: Wetzel S/A e Wlm Ind Com; c) para o ano de 2011: Aliansce, Aes Tiete e Afluente; d) para o ano de 2010: Lopes Brasil; e) para o ano de 2009: Vulcabras e; f) para o ano de 2008: Trans Paulist e Cor Ribeiro.

Empresas mais eficientes financeiramente, ao longo do tempo, poderiam apresentar maiores condições de se adequarem aos padrões de governança corporativa (Bernardino, Peixoto \& Ferreira, 2015), relação esta proposta neste estudo. Quando empresas se encontram interligadas os nós representam a ligação entre elas por terem a eficiência financeira como característica comum (eficiência $100 \%$ em todos os anos). No ano de 2010, somente uma empresa obteve $100 \%$ de eficiência ao analisar sua posição isolada, contudo, para outras empresas este ano também foi eficiente com dois ou mais períodos.

Foram extraídos os indicadores estatísticos em redes entre as empresas e seus respectivos níveis de eficiência, respeitando os anos aos quais encontravam-se vinculadas. A Tabela 2 apresenta os resultados. 
Influência da Estrutura de Governança Corporativa na Eficiência Financeira: Evidências de Empresas Brasileiras de Capital Aberto

Tabela 2 - Grau de centralidade das empresas com eficiência ao nível de 100\%

\begin{tabular}{|c|c|c|}
\hline Empresa & OutDegree & NrmDegree \\
\hline SPTURIS & 35 & $8,5 \%$ \\
\hline TARPON INV & 35 & $8,5 \%$ \\
\hline HERCULES & 35 & $8,5 \%$ \\
\hline OSX BRASIL & 13 & $3,2 \%$ \\
\hline ODONTOPREV & 13 & $3,2 \%$ \\
\hline TAESA & 13 & $3,2 \%$ \\
\hline RECRUSUL & 13 & $3,2 \%$ \\
\hline SCHLOSSER & 13 & $3,2 \%$ \\
\hline PORTOBELLO & 13 & $3,2 \%$ \\
\hline ODERICH & 13 & $3,2 \%$ \\
\hline OGX PETROLEO & 13 & $3,2 \%$ \\
\hline ENCORPAR & 13 & $3,2 \%$ \\
\hline PET MANGUINH & 13 & $3,2 \%$ \\
\hline VALE & 13 & $3,2 \%$ \\
\hline VULCABRAS & 11 & $2,7 \%$ \\
\hline MENEZES JR & 11 & $2,7 \%$ \\
\hline CETIP & 11 & $2,7 \%$ \\
\hline MENEZES CORT & 11 & $2,7 \%$ \\
\hline
\end{tabular}

\begin{tabular}{|c|c|c|}
\hline Empresa & OutDegree & NrmDegree \\
& & \\
\hline COBRASMA & 11 & $2,7 \%$ \\
\hline ELETROBRAS & 11 & $2,7 \%$ \\
\hline ALFA CONSORC & 11 & $2,7 \%$ \\
\hline ALFA HOLDING & 11 & $2,7 \%$ \\
\hline CEB & 11 & $2,7 \%$ \\
\hline VALID & 6 & $1,5 \%$ \\
\hline WLM IND COM & 6 & $1,5 \%$ \\
\hline WETZEL S/A & 6 & $1,5 \%$ \\
\hline WEG & 6 & $1,5 \%$ \\
\hline AES TIETE & 5 & $1,2 \%$ \\
\hline AFLUENTE & 5 & $1,2 \%$ \\
\hline BR PROPERT & 5 & $1,2 \%$ \\
\hline ALIANSCE & 5 & $1,2 \%$ \\
\hline PRUMO & 5 & $1,2 \%$ \\
\hline MONT ARANHA & 5 & $1,2 \%$ \\
\hline COR RIBEIRO & 4 & $1,0 \%$ \\
\hline TRAN PAULIST & 4 & $1,0 \%$ \\
\hline LOPES BRASIL & 3 & $0,7 \%$ \\
\hline
\end{tabular}

OutDegree (soma das ligações de um ator com as demais)

NrmDegree (valor em \% do OutDegree)

Fonte: Dados da pesquisa

As empresas que apresentaram um maior grau de associação com as demais foram Spturis, Tarpon Inv e Hercules. Esse resultado está relacionado às estas empresas, por essas possuírem grau máximo de eficiência financeira em todos os períodos analisados e revela a importância delas no contexto do estudo. Estas informações se tornam relevantes para que os gestores continuem a adotar as ações realizadas e trabalhem em novas estratégias para se manterem na liderança em relação à eficiência. A centralidade das empresas eficientes indica sua representatividade, principalmente porque elas tiveram eficiência de $100 \%$ em todos os anos analisados, empresas eficientes em menos anos se tornaram periféricas, entretanto também podem ser consideradas atraentes em investimentos. A Tabela 3 apresenta a estatística descritiva da posição das empresas na rede.

Tabela 3 - Estatística descritiva da rede

\begin{tabular}{|c|c|c|c|}
\hline & Grau de Centralidade (Degree) & $\begin{array}{c}\text { Média das somas das ligações das } \\
\text { empresas com as demais }\end{array}$ & Percentual \\
\hline Média & 11,44 & 32,69 & 0.028 \\
\hline Desvio-Padrão & 7,89 & 22.552 & 0.019 \\
\hline Somatório & 412 & 1177.143 & 1.000 \\
\hline Variância & 62,3 & 508.592 & 0.000 \\
\hline Mínimo & 3 & 8.571 & 0.007 \\
\hline Máximo & 35 & 00.000 & 0.085 \\
\hline \multicolumn{3}{|c|}{ Network Centralization $=71.26 \%$} \\
\hline
\end{tabular}

Fonte: Dados da pesquisa 
Os resultados da Tabela 2 indicam que a média das relações da rede, considerando-se todo o período analisado, é 11,44 e, seu somatório, em todo o período, é de 412 relações. O desvio-padrão aponta que o grau de centralidade das empresas no período analisado apresenta uma variação média de 7,89. As relações entre os anos variam de 3 (grau mínimo) até 35 (grau máximo). O grau de centralidade da rede apresentou um percentual de $71,26 \%$, que é resultado da quantidade de empresas presentes com níveis de eficiência no período.

\subsubsection{Influência da governança corporativa na eficiência financeira das empresas}

Com auxílio do software Stata versão 11.0, foram realizados os procedimentos estatísticos para analisar a influência da estrutura de governança corporativa na eficiência financeira das empresas. Foi realizado o procedimento estatístico para as variáveis de governança corporativa representada pelas suas dimensões acesso às informações, conteúdo das informações, estrutura do Conselho de Administração e estrutura de propriedade e controle e a eficiência financeira. A estatística descritiva das 268 observações é apresentada na Tabela 4.

Tabela 4 - Estatística descritiva das variáveis das empresas

\begin{tabular}{|c|c|c|c|c|}
\hline Variáveis & Média & Desvio-Padrão & Mínimo & Máximo \\
\hline DEA & 0,3988 & 0,2720 & 0 & 1 \\
\hline Acesso às informações & 0,9011 & 0,1804 & 0 & 1 \\
\hline Conteúdo das Informação & 0,7537 & 0,2649 & 0 & 1 \\
\hline Estrutura do Conselho & 0,4977 & 0,3015 & 0 & 1 \\
\hline Estrutura de Propriedade & 0,4850 & 0,2698 & 0 & 1 \\
\hline
\end{tabular}

Fonte: Dados da pesquisa

A média da variável eficiência financeira apresentou valor de 0,3988 , o que se pressupõe que o índice de eficiência, que variou de $1(100 \%)$ e 0 $(0 \%)$ entre a média da amostra, representa $39,88 \%$ do total de empresas. Entre as variáveis que representam a estrutura de governança o Acesso às Informações foi a variável que apresentou maior peso, revelando que $90,11 \%$ das empresas disponibilizavam desta informação. Por outro lado, a variável relacionada à governança com a menor média foi a Estrutura de Propriedade, que esteve presente em $48,5 \%$ da amostra.

$\mathrm{O}$ teste VIF permite verificar se existe multicolineariedade entre as variáveis, ou seja, identifica se os coeficientes gerados pela correlação são muito altos. Quando isso ocorre, o valor de uma variável é alto e, consequentemente, o coeficiente das demais é reduzido (Gujarati, 2006). A Tabela 6 apresenta o valor de VIF das empresas para verificar se as variáveis independentes são correlacionadas.

Tabela 5 - Valores de VIF das empresas

\begin{tabular}{|c|c|c|}
\hline Variáveis & VIF & 1/VIF \\
\hline Acesso às informações & 1,48 & 0,6902 \\
\hline Conteúdo das informações & 1,59 & 0,6278 \\
\hline Estrutura do Conselho & 1,93 & 0,5168 \\
\hline Estrutura de Propriedade & 1,57 & 0,6373 \\
\hline Setor & 1,01 & 0,9904 \\
\hline Média do VIF & $\mathbf{1 , 5 1}$ & - \\
\hline
\end{tabular}

Fonte: Dados da pesquisa 
Os valores de VIF apresentaram-se dentro dos padrões aceitáveis. Gujarati (2006) ressalta que quando uma variável apresenta coeficiente de VIF maior do que 10, indica que existe multicolineariedade. Para verificar se havia problema de heterocedasticidade, foi realizado o teste de Breusch-Pagan e Cook-Weisberg verificando a aderência do modelo. Os resultados indicaram um $\mathrm{Chi}^{2}(1)=1,64$ e Prob $>\mathrm{Chi}^{2}=0,20$, sugerindo que não houveram problemas de heterocedasticidade, uma vez que o valor $p$ foi superior à 0,05 .

Foi estimado o coeficiente de regressão para verificar a influência das variáveis independentes, representadas pela estrutura de governança, na variável dependente eficiência financeira das empresas. A Tabela 7 apresenta os resultados.

Tabela 6 - Coeficiente da regressão das empresas

\begin{tabular}{|c|c|c|c|c|c|c|}
\hline Eficiência Financeira DEA & Coeficiente & Erro Padrão & $\mathbf{t}$ & P>t & \multicolumn{2}{|l|}{ 95\% Intervalo de Confiança } \\
\hline Acesso às informações & 0,1424 & 0,1189 & 1,20 & 0,232 & $-0,0917$ & 0,3767 \\
\hline Conteúdo das informações & 0,1228 & 0,0810 & 1,51 & 0,131 & $-0,0368$ & 0,2824 \\
\hline Estrutura do Conselho & $-0,1873$ & 0,0792 & $-2,36$ & 0,019 & $-0,3433$ & $-0,0313$ \\
\hline Estrutura de Propriedade & 0,1796 & 0,0755 & 2,38 & 0,018 & 0,0309 & 0,3282 \\
\hline Setor & 0,001 & 0,0027 & 0,63 & 0,528 & $-0,0036$ & 0,0071 \\
\hline Constante & 0,3178 & 0,1656 & 1,92 & 0,056 & 0,0083 & 0,5992 \\
\hline
\end{tabular}

Fonte: Dados da pesquisa

Os resultados dos valores absolutos da regressão indicam que a relação entre a eficiência financeira e a estrutura de governança é explicada por $4,48 \%\left(\mathrm{R}^{2}\right.$ ajustado $\left.=0,0448\right)$ pelas variáveis Estrutura do Conselho e Estrutura de Propriedade, ao nível de significância de $95 \%$. O resultado encontrado apresenta baixo poder de explicação sobre a influência da estrutura de governança corporativa no desempenho financeiro das empresas e evidencia que existem outras variáveis, não especificadas neste estudo, que interferem na eficiência financeira. Os resultados indicaram que a Estrutura do Conselho afeta negativamente a eficiência das empresas $(-0,1873)$, enquanto a Estrutura de Propriedade afeta positivamente $(0,1796)$. A equação da regressão que explica o modelo é:

\section{Eficiência Financeira $($ DEA $)=-0,1873$ (EstruturaConselho $)+0,1796$ (EstruturaPropriedade $)+0,3178$ (Constante) .}

O resultado da eficiência financeira, variável dependente, considerou no seu cálculo o Faturamento, o Lucro Operacional Líquido (Lol), o Lucro Operacional Bruto (Lob) e o Resultado sobre o Patrimônio Líquido (Rspl). A eficiência está relacionada negativamente à Estrutura do Conselho
$(-0,1873)$ que avalia a presença de pessoas diferentes nos cargos de diretor executivo e presidente do conselho, deste possuir entre 5 e 9 membros, da presença, de acordo com acionistas, e um mandato de 1 a 2 anos. A Estrutura de Propriedade influencia a eficiência positivamente e está relacionada a emissão de ações com direito ao voto, ao controlador ter menos de $70 \%$ das ações ordinárias, de as ações preferenciais emitidas serem menos de $50 \%$ das ordinárias, a emissão de Adr e a concessão de tag along.

\subsection{Apresentação dos resultados para as instituições financeiras}

\subsubsection{Análise da eficiência financeira das instituições financeiras}

Procedeu-se o mesmo cálculo para uma amostra de 16 instituições financeiras. A eficiência foi calculada com o Excel® e com o auxílio do Solver, foram identificados os bancos eficientes em relação às variáveis Faturamento, Lucro Operacional Líquido (Lol), Lucro Operacional Bruto (Lob) e Resultado sobre o Patrimônio Líquido (Rspl) para cada período analisado (2008 a 2013). A Figura 6 ilustra a evolução da eficiência dos bancos eficientes no período de 2013 a 2008. 
Influência da Estrutura de Governança Corporativa na Eficiência Financeira: Evidências de Empresas Brasileiras de Capital Aberto

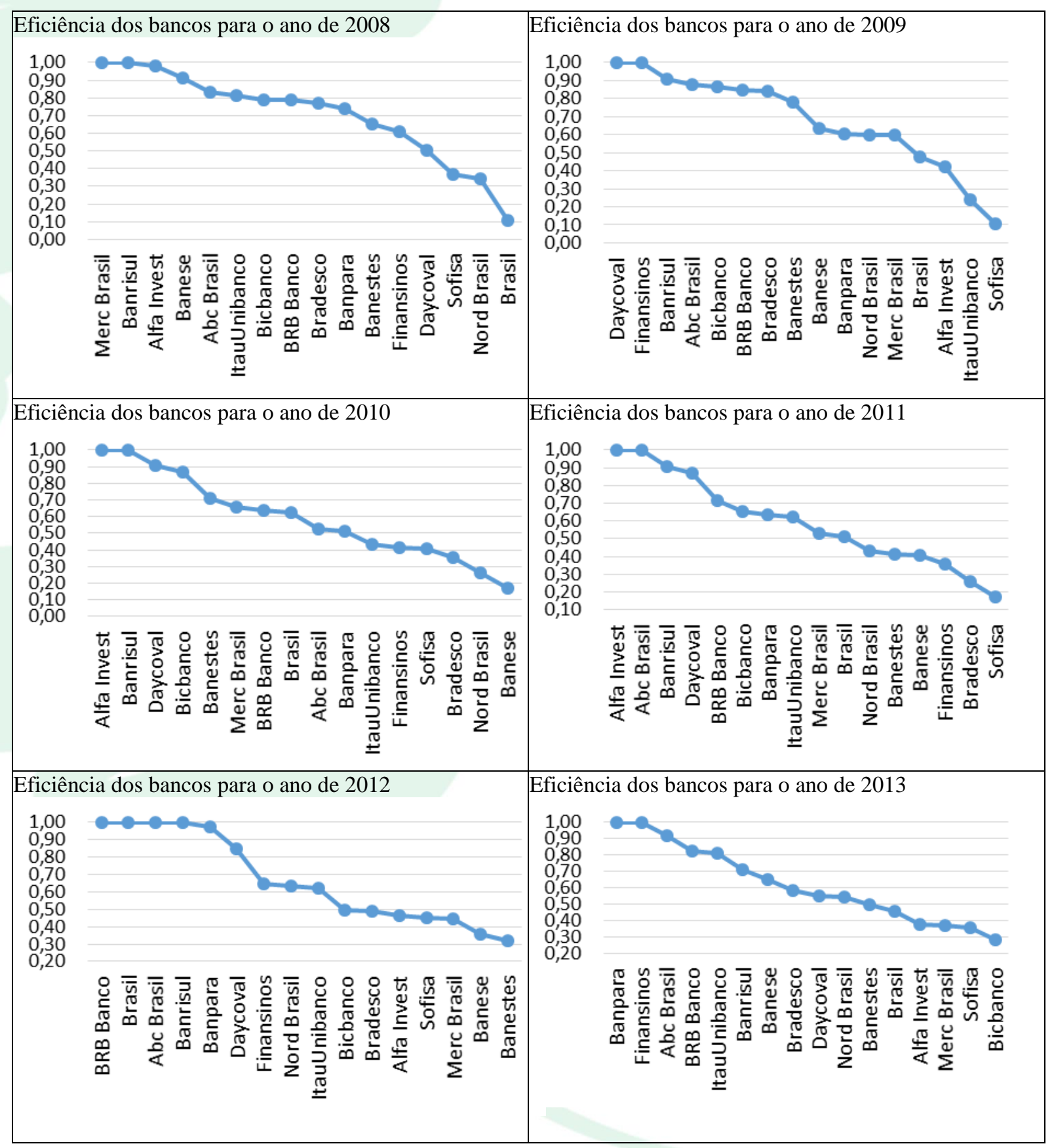

Figura 6: Evolução das eficiências dos bancos no período de 2008 a 2013

Fonte: Dados da pesquisa

Os resultados da eficiência financeira dos bancos se apresentaram estáveis ao longo dos seis anos. Houve um leve aumento no número de instituições ao nível máximo de eficiência nos anos de 2010 e 2012. O banco Banrisul apresentou nível de eficiência de $100 \%$ para os anos de 2008, 2010 e 2013, se destacando entre as instituições desta natureza. Outro grupo de empresas apresentaram eficiência máxima por dois períodos: Daycoval (2009 e 2010), Financinos (2009 e 2013), Alfa Invest (2010 e 2011) e ABC Brasil (2011 e 2013). Obtiveram eficiência máxima em um período os bancos: Mer Brasil (2008), BRB Banco e Brasil (2012) e Banpara (2013). O índice de eficiência financeira variou, nos demais períodos, entre $10 \%$ e $98 \%$. 
Influência da Estrutura de Governança Corporativa na Eficiência Financeira: Evidências de Empresas Brasileiras de Capital Aberto

4.2.2 Influência da governança corporativa na eficiência financeira das instituições financeiras

Para analisar a influência da estrutura governança corporativa na eficiência financeira dos bancos, foi realizado, com auxílio do software Stata versão 11.0, as análises estatísticas. A Tabela 8 apresenta o resultado das estatísticas descritivas das 16 observações.

Tabela 7 - Estatística descritiva dos bancos

\begin{tabular}{|c|c|c|c|c|}
\hline Variáveis & Média & Desvio Padrão & Mínimo & Máximo \\
\hline DEA & 0,6200 & 0,2355 & 0,2800 & 1 \\
\hline Acesso às informações & 0,8303 & 0,1823 & 0,4286 & 1 \\
\hline Conteúdo das informações & 0,7500 & 0,2581 & 0,5000 & 1 \\
\hline Estrutura do Conselho & 0,4250 & 0,3000 & 0 & 0,8000 \\
\hline Estrutura de Propriedade & 0,2187 & 0,2015 & 0 & 0,5000 \\
\hline
\end{tabular}

Fonte: Dados da pesquisa

A média da eficiência financeira, apresentou valor de 0,62. Isso indica que a maior parte dos bancos apresenta eficiência financeira superior a $60 \%$. As variáveis Acesso às Informações e Conteúdo das Informações resultaram em valores consideráveis, 0,8303 e 0,7500 .
O teste VIF foi realizado com o propósito de verificar se havia multicolineariedade entre as variáveis, ou seja, se as variáveis independentes são correlacionadas. A Tabela 10 apresenta esses valores.

Tabela 8 - Valores de VIF das instituições financeiras

\begin{tabular}{|c|c|c|}
\hline Variáveis & VIF & $\mathbf{1 / V I F}$ \\
\hline Acesso às informações & 1,23 & 0,7908 \\
\hline Conteúdo das informações & 1,19 & 0,8414 \\
\hline Estrutura do Conselho & 1,51 & 0,6630 \\
\hline Estrutura de Propriedade & 1,38 & 0,7229 \\
\hline Média do VIF & $\mathbf{1 , 3 3}$ & - \\
\hline
\end{tabular}

Fonte: Dados da pesquisa

Os resultados obtidos encontram-se dentro do aceitável e indicam que não há multicolineariedade, ou seja, a correlação não se mostrou em alguma variável que poderia reduzir o poder de explicação das demais. Também foi realizado o teste de Breusch-Pagan e CookWeisberg para verificar se havia heterocedasticidade. Os resultados indicaram um
$\mathrm{Chi}^{2}(1)=0,01$ e Prob $>\mathrm{Chi}^{2}=0,9223$, considerado aceitável na aderência ao modelo.

Foi realizado o cálculo do coeficiente de regressão para verificar a influência das variáveis independentes, representadas pela estrutura de governança, na variável dependente eficiência financeira dos bancos. Na Tabela 9, apresentam-se os resultados.

Tabela 9 - Coeficiente da regressão dos bancos

\begin{tabular}{|c|c|c|c|c|c|c|}
\hline Eficiência Financeira DEA & Coeficiente & Erro Padrão & $\mathbf{t}$ & \multicolumn{1}{|c|}{ P>t } & \multicolumn{2}{|c|}{ 95\% Intervalo de Confiança } \\
\hline Acesso às informações & 0,9797 & 0,4357 & 2,25 & 0,046 & 0,0207 & 1,9388 \\
\hline Conteúdo das informações & $-0,4985$ & 0,2298 & -2.17 & 0,053 & $-1,0044$ & 0,0073 \\
\hline Estrutura do Conselho & $-0,7150$ & 0,2671 & $-2,68$ & 0,022 & $-1,3031$ & $-0,1269$ \\
\hline Estrutura de Propriedade & 0,1771 & 0,3038 & 0,58 & 0,572 & $-0,4916$ & 0,8458 \\
\hline Constante & 0,4455 & 0,2809 & 1,59 & 0,141 & 0,1727 & 1,0637 \\
\hline
\end{tabular}

Fonte: Dados da pesquisa

A relação entre a eficiência financeira e a estrutura de governança dos bancos é explicada com um percentual de $44,58 \%\left(R^{2}=0,4458\right)$ pelas variáveis Acesso às Informações, Conteúdo das
Informações e Estrutura do Conselho. A equação da regressão que explica o modelo é: 
Eficiência $($ DEA $)=0,9797$ (Acesso Informação) 0,4985(Conteúdo Informações) - 0,7150 (Estrutura Conselho)

$\mathrm{O}$ Acesso à Informações influencia a eficiência financeira positivamente, de forma que, empresas que possuem um maior acesso à informação apresentam também, uma maior eficiência. Esta variável era composta por questões sobre o banco possuir um website, se neste haviam informações relativas à governança corporativa, se as informações financeiras eram apresentadas nele, se o website era bilíngue e se a empresa possuía uma sessão específica de relações com investidores.

O conteúdo das informações influencia a eficiência financeira negativamente, desta forma, não significa que empresas que divulgam em seus RAs informações relativas a governança e que publicam seus relatórios financeiros na data exigida terão um desempenho superior, ao contrário, ele tende a reduzir. A variável Estrutura do Conselho da Administração se mostrou contrária a eficiência, ao apresentar um valor negativo de $-0,7150$. Isto indica que a estrutura do Conselho da Administração não influencia o aumento da eficiência, pelo contrário, a presença desse conselho reduz a eficiência destas empresas. Estão relacionadas a esta variável, a existência de um Conselho de Administração de 5 a 9 membros, de pessoas diferentes ocuparem os cargos de presidente do conselho e diretor da empresa, de os membros do conselho possuírem um mandato de um a dois anos e de a empresa possuir acordo de acionistas.

\section{CONSIDERAÇÕES FINAIS}

Este estudo objetivou analisar a influência da governança corporativa na eficiência financeira das empresas de capital aberto listadas na Bolsa de Valores de São Paulo (BM\&Fbovespa). A governança corporativa foi representada pelas variáveis acesso às informações, conteúdo das informações, estrutura do Conselho de Administração e estrutura de propriedade e controle. A eficiência foi mensurada por meio da Análise por Envoltória de Dados (DEA).

A análise da eficiência financeira dos bancos ao longo dos seis anos analisados manteve-se estável e superior ao das empresas, tanto em relação ao percentual equivalente de empresas com eficiência máxima, quanto em relação ao índice geral de eficiência. Esse resultado se justifica objeto de comercialização de instituições financeiras ser o agregado financeiro e, em razão disso, atenderem a demanda por crédito e as expectativas de aplicações de agentes poupadores, movimentam um volume de recursos financeiros que se encontram relacionados a situação econômica do país (Mendonça \& Sachsida, 2013).

Verificou-se, neste estudo, que a governança corporativa influencia o desempenho financeiro das empresas nas dimensões estrutura do Conselho de Administração e estrutura de propriedade, oferecendo suporte para confirmar a terceira e a quarta hipótese, no entanto, seu poder de explicação foi baixo, salientando que outras variáveis não especificadas poderão interferir nesta relação. Um ponto peculiar é que o Conselho de Administração influencia negativamente o desempenho financeiro das empresas, resultado similar ao encontrado por Sonza (2012) que verificou uma relação negativa entre o presidente do Conselho de Administração também ocupar o cargo de executivo com a eficiência. Por outro lado, a eficiência é influenciada positivamente pela estrutura de propriedade, assim, emitir de ações com direito ao controlador ter menos de $70 \%$ das ações ordinárias, de as ações preferenciais emitidas serem menor do que $50 \%$ das ações ordinárias, a emissão de ADR e a concessão de tag along contribuem para eficiência financeira. A primeira e a segunda hipóteses não se mostraram significativas neste estudo.

Os resultados para os bancos evidenciaram diferentes dimensões da governança corporativa que influenciaram a eficiência financeira, as quais apresentaram um percentual de explicação adequado ao modelo. Desta forma, o acesso às informações, o conteúdo das informações e a estrutura do Conselho de Administração foram significativas, confirmando a primeira, a segunda e a terceira hipóteses deste estudo. Ficou evidente, para os bancos, que disponibilizar as informações técnicas, financeiras e contábeis contribuem para uma maior eficiência financeira destas instituições, o que pode estar relacionado também com a estrutura de atividade dos bancos. O conteúdo das informações contribui para redução da eficiência financeira, ressaltando que divulgar informações relativas a governança corporativa nos relatórios financeiros e a publicação destes na data exigida apresentarão uma eficiência financeira inferior. Assim como para as empresas, a presença do Conselho de Administração, para os bancos, apresentou resultados negativos. Os resultados não suportaram a confirmação da quarta hipótese.

Este estudo contribui para identificação das dimensões da governança corporativa que influenciam a eficiência de empresas e bancos e também coopera com a identificação de instituições eficientes ao longo de seis anos. Os elementos da governança corporativa que se apresentaram 
inversos à eficiência financeira poderiam ser analisados com maior profundidade, pois estes elementos deveriam atuar favoráveis a eficiência. Este estudo se limitou a investigar a influência da governança corporativa na eficiência financeira para o ano de 2013, por conta disso, futuras investigações poderiam coletar informações sobre índice Igov nos próximos anos e utilizar métodos econométricos de séries temporais para análise, como dados em painel.

\section{REFERÊNCIAS}

Adams, R. B., Hermalin, B. E. \& Weisbach, M. S. (2010) The role of boards of directors in corporate governance: a conceptual framework and survey. Journal of Economic Literature, 48(1), 58-107.

Berle, A. \& Means, G. (1932) The modern corporation and private property. New York: Macmillan.

Beuren, I. M., Nascimento, S. do \& Rocha, I. (2013) Nível de evidenciação ambiental e desempenho econômico de empresas: aplicando a análise envoltória de dados. Future Studies Research Journal, 5(1), 198-226, jan./jun.

Berger, A. N., Hunter, W. C. \& Timme, S. G. (1993) The efficiency of financial institutions: a review and preview of research past, presente, and future. Journal of Banking of Finance, 17, 221-249.

Berger, A. N. \& Humphrey, D. B. (1997) Efficiency of financial institutions: international survey and directions for future research. European Journal of Operational Research, Special Issue.

Berger, A. N. \& Mester, L. J. (1997) Inside the black BOX: what explains differences in the efficiencies of financial institutions? Journal of Banking and Finance, 21.

Bernardino, F. F. M., Peixoto, F. M. \& Ferreira, R. do N. (2015) Governança e eficiência em empresas do setor elétrico brasileiro. Pretexto, 16(1), 36-51.

Carneiro, J. \& Silva, J. F. da. (2010) Medidas contábeis-financeiras como indicadores de desempenho organizacional: análise crítica de sua conceituação e operacionalização. Revista Eletrônica de Gestão de Negócios, 6(3),31-68.

Catapan, A. \& Colauto, R. D. (2014) Governança corporativa: uma análise de sua relação com o desempenho econômico-financeiro de empresas cotadas no Brasil nos anos de 2010-2012. Contaduría \& Administración, 59(3),137-164.

Charnes, A., Cooper, W. W. \& Rhodes, E. (1978) Measuring the efficiency of decision making units. European Journal of Operational Research, 2, 429-444.

Demirbas, D., \& Yukhanaev, A. (2011) Independence of board of directors, employee relation and harmonisation of corporate governance: Empirical evidence from Russian listed companies. Employee Relations, 33(4): 444-471.

Eisenhard, K. M. (1989) Agency theory: an assessment and review. Academy of Management Review, 31, 488-511.

Farhi, M. \& Borghi, R. A. Z. (2009) Operações com derivativos financeiros das corporações de economias emergentes. Estudos Avançados, 23, 66.

Ferreira, R. N. (2012) Eficiência das práticas de governança corporativa no Brasil. Tese de doutorado em Administração. Universidade Federal de Lavras, Lavras.

Ferreira, R. N., Santos, A. C. dos, Lopes, A. L. M., Nazareth, L. G. C. \& Fonseca, R. A. (2013) Governança corporativa, eficiência, produtividade e desempenho. Revista de Administração da Mackenzie, 14(4),134-164.

Gujarati, D. N. (2006). Econometria básica. (2. Ed.) Rio de Janeiro: Elsevier.

Instituto Brasileiro de Governança Corporativa (IBCG). (2010) Código das melhores práticas de governança corporativa. (4.ed.) Instituto Brasileiro de Governança Corporativa. São Paulo, SP: IBCG.

Iudícibus, S., Martins, E., Gelbcke, E. R., \& Santos, A. dos. (2010) Manual de contabilidade societária: aplicável a todas as sociedades de acordo com as normas internacionais e do $C P C$. São Paulo: Atlas. 
Kassai, S. (2002) Utilização da Análise por Envoltória de Dados (DEA) na análise de demonstrações contábeis. Tese de Doutorado inédita. Faculdade de Economia, Administração e Contabilidade, da Universidade de São Paulo. São Paulo, São Paulo.

Kumar, P., \& Zattoni, A. (2013) Editorial: corporate governance, board of directors, and firm performance. Oxford: Blackwell.

Loureiro, D. Q., Gallon, A. V. \& De Luca, M. M. M. de. (2011) Subvenções e assistências governamentais (SAGs): evidenciação e rentabilidade das maiores empresas brasileiras. Revista de Contabilidade e Organizações, 5(13), 34-54.

Maroco, J. (2003) .Análise estatística. (2. ed._ Lisboa: Edições Silabo.

Melkumov, D. (2009) Institutional background as a determinant of boards of directors internal and external roles: the case of Russia. Journal of World Business, 44, 94-103.

Peixoto, F. M. (2012) Governança corporativa, desempenho, valor e risco: estudo das mudanças em momentos de crise. Tese de doutorado em Administração. Universidade Federal de Minas Gerais, Belo Horizonte.

Peixoto, F. M., Ferreira, R. N. \& Lopes, A. L. M. (2011) Corporate governance and performance in the electricity sector using data envelopment analysis: a study in the Brazilian capital market. Proceedings of Conference on Performance
Measurement and Management Control. The European Institute for Advanced Studies in Management.

Peña, C. A. (2008) Um modelo de avaliação da eficiência da administração pública através do método de Análise Envoltória de Dados (DEA). Revista de Administração Contemporânea, 12(1), 83-106.

Perez, M. M. \& Famá, R. (2006) Ativos intangíveis e o desempenho empresarial. Revista de Contabilidade \& Finanças, 17:40, 7-24.

Silveira, A. di. M. da. (2004) Governança corporativa e estrutura de propriedade: determinantes e relação com o desempenho das empresas no Brasil. Tese de Doutorado inédita, Faculdade de Economia, Administração e Contabilidade, da Universidade de São Paulo, São Paulo, São Paulo.

Sonza, I. B. (2012) Eficiências entre estruturas de propriedades concentradas e compensação de executivos: novas evidências para o Brasil. Tese de doutorado em administração. Universidade Federal do Rio Grande do Sul, Porto Alegre.

Sonza, I. B. \& Kloeckner, G. de O. (2014) A governança corporativa influencia a eficiência das empresas brasileiras? Revista de Contabilidade e Finanças, 25(65),145-160.

Williamson, O. E. (1996) Economic organization: the case for candor. Academy of Management Review, 21, 48-57. 